\title{
A pandemia do coronavírus e a escalada do poder militar no Estado brasileiro
}

The Coronavirus pandemic and the military escalation in the Brazilian state

La pandemia de coronavirus y la escalada del poder militar en el Estado

brasileño

La pandémie du coronavirus et l'escalade du pouvoir militaire dans l'État

Brésilien

\section{Pedro Henrique Pedreira Campos}

\section{OpenEdition}

\section{Journals}

\section{Edição electrónica}

URL: http://journals.openedition.org/espacoeconomia/13177

DOI: 10.4000/espacoeconomia.13177

ISSN: 2317-7837

\section{Editora}

Núcleo de Pesquisa Espaço \& Economia

\section{Refêrencia eletrónica}

Pedro Henrique Pedreira Campos, « A pandemia do coronavírus e a escalada do poder militar no Estado brasileiro », Espaço e Economia [Online], 18| 2020, posto online no dia 23 abril 2020, consultado o 20 maio 2020. URL : http://journals.openedition.org/espacoeconomia/13177 ; DOI : https://doi.org/10.4000/espacoeconomia.13177

Este documento foi criado de forma automática no dia 20 maio 2020

(C) NUPEE 


\section{A pandemia do coronavírus e a escalada do poder militar no Estado brasileiro}

The Coronavirus pandemic and the military escalation in the Brazilian state

La pandemia de coronavirus y la escalada del poder militar en el Estado

brasileño

La pandémie du coronavirus et l'escalade du pouvoir militaire dans l'État

Brésilien

Pedro Henrique Pedreira Campos

Agradeço a leitura atenta e os valiosos comentários de Flora Daemon. Suas precisas indicações ajudaram a reduzir as imperfeições deste texto. Obviamente ela não deve ser creditada pelos equívocos deste ensaio.

\section{Introdução}

1 Em meados do mês de abril de 2020, foi difundido nas redes sociais e plataformas de informação o vídeo do prefeito do município de Três Rios, no estado do Rio de Janeiro, em que relata o recebimento de um ofício do Exército solicitando informações a respeito da capacidade de sepultamento que a cidade possuía. Vários outros prefeitos fluminenses indicaram terem recebido documento similar do Comando Militar do Leste (sede do I Exército), com o pedido de informações a respeito da quantidade de cemitérios, sepulturas e capacidade de enterros diários por parte do município (G1, 2020). Para além da sensação de angústia e temor de uma mortandade em larga escala que tal notícia gera, há a evidência da atuação militar em um terreno que constitucionalmente não é originalmente o seu. Assim, as forças armadas se autorizaram a exercer o papel de uma instituição que vai colher informações e, possivelmente, agir em meio à crise de alastramento do novo coronavírus na população brasileira. O documento parece ser indicativo do novo papel que vêm assumindo os 
militares na cena pública do país, incorporando funções e atividades que antes não configuravam como suas áreas de ação.

2 O propósito deste texto é fazer um breve balanço do papel exercido pelos militares em meio à difusão da Covid-19 na sociedade brasileira. É importante salientar que não dispomos de especialidade no tema e não fizemos um estudo criterioso da questão, ainda em andamento e com a possibilidade aberta de muitos rearranjos e desdobramentos repentinos e não-previstos. A proposta não é realizar uma análise exaustiva ou profunda do papel exercido pelos militares no ambiente político brasileiro nos últimos anos, mas sim desenvolver um ensaio no qual se coloca a hipótese de escalada da presença dos integrantes das forças armadas na cena pública brasileira no período atual, com a possibilidade aberta de aceleração desse processo em meio à grave crise derivada do alastramento da epidemia do novo coronavírus junto à população do país. Assim, gostaríamos de salientar os limites do presente texto, que se coloca enquanto um trabalho ensaístico, para intervenção e fomento do debate, mais do que o fruto de uma pesquisa ou um estudo cuidadoso da questão. Pelo contrário, uma das nossas conclusões reside justamente na indicação da necessidade de mais investigações acerca dos militares brasileiros, suas frações e urgência de reflexão profunda em torno da ação política da categoria recentemente.

\section{O surto do novo coronavírus e a escalada militar no mundo e no Brasil}

4 O alastramento da pandemia do novo coronavírus no mundo desde o início do ano de 2020 tem levado ao uso deliberado da metáfora militar por parte dos líderes políticos de algumas das principais potências do planeta. A chanceler alemã Angela Merkel indicou que o combate ao vírus era o principal desafio do país desde o final da II Guerra Mundial. $\mathrm{O}$ presidente francês tem feito discursos nos quais repete insistentemente a ideia de que o país está em guerra contra a difusão da doença, justificando assim medidas de isolamento social, quarentena e menor mobilidade das pessoas. Já o presidente dos EUA também usa o linguajar militar para se referir ao combate à pandemia, utilizando também a epidemia como motivo para reter equipamentos de saúde em território norte-americano e aplicar uma ação comercial agressiva para dispor de preferência nas compras internacionais dos insumos de saúde para prevenção e tratamento da doença (EL PAÍs, 2020).

5 A escalada militar tem ocorrido nos últimos anos em diversos países do mundo, sem relação direta com a pandemia do novo Coronavírus. Além da ascensão dos integrantes das forças armadas no Brasil, a presença desses agentes na política nacional tem se reforçado em diversas outras regiões do globo. Assim, parece emblemático o desfecho do levante popular da "Primavera Árabe" no Egito, com uma intervenção militar que depôs um governo democraticamente eleito e implantou uma ditadura no país, liderada pelos generais do exército (COSTA, 2020). Em outra cena de ativismo político militar recente, foi notório o golpe de Estado imposto pelos militares em 2019 na Bolívia, em oposição ao resultado eleitoral que garantia mais um mandato presidencial ao líder Evo Morales no país. No caso, um general do Exército foi publicamente em traje fardado recomendar que o presidente legítimo do país renunciasse, indicando que não poderia 
conter as consequências caso isso não ocorresse. É evidente que tal ação caracteriza um golpe de Estado de perfil militar, com o uso da força. Nessa situação, a ação esteve relacionada a interesses internacionais e locais em torno da exploração mineral de insumos da indústria de computadores e celulares (BRASIL DE FATO, 2019).

6 No Brasil, a emergência dos militares na cena pública ocorreu em meio à crise política atravessada no país durante a última década. Após uma submersão e afastamento do processo decisório com o final da ditadura civil-militar, as forças armadas têm voltado ao centro do xadrez político do país no compasso da própria escalada dos impasses políticos que têm vindo à tona nos últimos anos. De acordo com João Roberto Martins Filho (2019), raro especialista a respeito dos militares nos dias atuais, o principal agente responsável pela organização do ingresso dos militares na vida política do país recentemente é o general do Exército Eduardo Villas-Bôas, que chefiou a força entre 2015 e 2019. É dele o famoso tuíte divulgado pelo Jornal Nacional na véspera da votação no plenário do Supremo Tribunal Federal (STF) a respeito da possibilidade de prisão após tramitação em segunda instância e que acabou sendo decisiva para a detenção do ex-presidente Luís Inácio Lula da Silva ${ }^{1}$.

7 A ação militar no processo político brasileiro obviamente não se restringe ao período recente. Pelo contrário, os agentes das forças armadas, não descolados das classes sociais e pressupostos políticos e ideológicos que permeiam certos grupos sociais, historicamente têm cumprido um papel decisivo na vida política do país, sobretudo no período republicano. Desde o golpe de Estado desferido por liderança militar em 1889, esses agentes têm realizado seguidas intervenções no processo político, culminando com o golpe de Estado de 1964 e a ditadura civil-militar de mais de duas décadas que vigorou desde então, liderada por oficiais militares. Segundo o especialista no tema, Alfred Stepan (1975 [1971]), com este último episódio, os militares brasileiros romperam com o padrão moderador que eles cumpriam na política brasileira até então, com intervenções pontuais, como as aplicadas em 1945, 1954, 1956, 1961, dentre outras ocasiões anteriores ao golpe de 1964.

8 Após o fim da ditadura, deu-se um longo período de submersão, com restrições seguidas ao poder da corporação e limitações até hoje não aceitas - como a implementação do ministério civil da Defesa, em 1999, durante o governo Fernando Henrique Cardoso -, no qual os militares se debruçaram sobre outras agendas e passaram a disputar o orçamento público, buscando recursos para os seus projetos, em particular na área nuclear, com a Marinha, no campo da cibernética, com o Exército, e no ramo aeroespacial, no caso da Aeronáutica (LEMOS, 2016). Além disso, envolviam-se em ações como as missões de paz - com destaque para a intervenção militar no Haiti, na qual vários dos militares que hoje atuam no governo Bolsonaro se formaram e desenvolveram experiências que ganharam destaque e exposição pública -, além das ações militares para "pacificação" de regiões das cidades brasileiras, como as intervenções armadas em favelas e comunidades pobres da cidade do Rio de Janeiro. Esse último processo já expressava uma crescente militarização da política pública de segurança, o que passou a ser alardeada como exemplo positivo por parte de grupos da mídia empresarial.

9 Durante o governo Lula, alguns projetos militares ganharam destaque e foram desenvolvidos programas de reequipamento das forças armadas, com atendimento do pleito da cúpula militar. Por mais que tenha havido momentos de tensão, principalmente nos anos iniciais do seu governo, em torno de questões como os soldos 
dos militares e a política de memória em relação ao período da ditadura, a impressão que se tem é que ao final do segundo mandato do ex-presidente Lula tenha havido um contentamento na corporação, tendo em vista a elevação dos recursos orçamentários, bem como o avanço em projetos como o do submarino nuclear da marinha e os programas como a Estratégia Nacional de Defesa (END) e o Plano Nacional de Defesa (FERREIRA NETO, 2020).

10 No entanto, ao longo do primeiro mandato de Dilma Rousseff, a relação dos generais da ativa e da reserva com o governo petista se esgarçou. De acordo com João Roberto Martins Filho (2019), alguns fatores podem explicar esse distanciamento da cúpula militar com o PT e o seu governo. Ele afirma que a ideologia anti-corrupção foi abraçada pela corporação militar de forma bastante acrítica, fazendo com que boa parte da caserna aderisse ao movimento anti-petista que ganhou força na sociedade brasileira, em particular entre 2014 e 2018 com as ações da operação Lava Jato. 0 mesmo autor destaca que nunca houve de fato uma aceitação por parte dos principais oficiais militares com o fato de um ex-operário e uma antiga guerrilheira da resistência armada à ditadura terem chegado à presidência da República. Por fim, Martins Filho aponta a Comissão Nacional da Verdade (CNV), instituída no ano de 2011, como um elemento fundamental que afastou as lideranças petistas da corporação, tendo em vista que incomodou os militares em relação a uma questão muito delicada que diz respeito ao processo de reparação, verdade e justiça em relação aos crimes cometidos durante o regime de exceção. A respeito desse ponto, o ex-presidente Lula, ainda preso, afirmou em entrevista que também considerava que a CNV tinha constituído um fator decisivo para o descontentamento militar com o governo Rousseff (LULA, 2019).

11 É importante salientar que, apesar da provável centralidade que a CNV teve para a contrariedade das forças armadas com os governos petistas, tal iniciativa foi fruto de uma condenação internacional do país e possuía horizontes bastante limitados, ainda mais quando comparado com o alcance das ações de reparação aplicadas em outros países. Assim, a CNV foi estabelecida após uma condenação do Estado brasileiro na Corte Interamericana de Direitos Humanos (CIDH), ligada à Organização dos Estados Americanos (OEA). De acordo com tratados dos quais o país é subscritor, o governo Rousseff atendeu à condenação internacional e implementou no primeiro ano de seu mandato a Comissão Nacional da Verdade, com uma composição bastante heterogênea e nada promissora no que tange um processo real de revisão histórica e aplicação da justiça no país em relação aos crimes perpetrados pelos agentes de Estado durante a ditadura brasileira. Pelo contrário, o que se verificou foi uma iniciativa bastante tímida em seu alcance e com vários integrantes que agiam no sentido de limitar a capacidade de enfrentamento com os militares e aprofundamento do conhecimento acerca das graves violações cometidas ao longo do regime de exceção. $\mathrm{O}$ funcionamento torpe da comissão e o pouco avanço no sentido de aplicar a justiça em relação aos crimes cometidos durante a ditadura revelam mecanismos forjados no processo de transição no país e uma distância muito significativa em relação aos horizontes mais significativos alcançados pelo processo de verdade, reparação e justiça atingidos em países como a Argentina (LEMOS, 2016).

12 Dessa forma, os militares se alinharam a uma oposição ao governo petista e estiveram diretamente envolvidos no golpe de 2016, apoiando a deposição da presidenta Dilma Rousseff e a ascensão de Michel Temer. Esse processo coincidiu com uma escalada do poder militar no Brasil e uma série de retrocessos. Um deles diz respeito ao recuo 
sentido no Ministério da Defesa. A contragosto dos militares, em 1999, o governo Cardoso unificou o comando das três forças em uma pasta ministerial, dotando-a de perfil civil. A ideia que lastreia essa proposta é a de que a defesa e segurança nacional não constituem um assunto restrito aos militares, mas um problema do Estado brasileiro e que deve constar enquanto uma política pública aplicada pelos representantes eleitos pela população e não pelos agentes da corporação militar, que contam com as suas próprias regras de hierarquia e ascensão funcional. Assim, as forças armadas brasileiras davam um passo no sentido da profissionalização, submetendo-se ao poder civil, eleito pela população. Desde 1999 até o governo Temer, todos os chefes da pasta da Defesa foram agentes civis, não-militares, o que constituía um avanço na transição da ditadura para a democracia e na implementação de um perfil profissional das forças armadas, submetidas ao poder das instituições democráticas, o que é inspirado no modelo do Ministério da Defesa francês. No entanto, o presidente Michel Temer nomeou um general para o cargo de ministro da Defesa, o que, apesar de não ser impedido por lei, constitui um retrocesso no sentido do que se previu para o Ministério da Defesa e simbolicamente representa a quebra do seu sentido, retornando a questão da defesa e da segurança nacional à tutela militar.

13 A escalada da presença militar no governo e nas próprias políticas públicas foi ainda mais reforçada após as eleições de 2018. Com a eleição de uma chapa composta por um antigo oficial militar de baixa patente - Jair Bolsonaro, ex-capitão do Exército - e pelo general da reserva Hamilton Mourão, figuras associadas à carreira das forças armadas voltavam à condução política do país. Em outros momentos, militares ocuparam a posição da presidência da República pela força (como no caso de Deodoro da Fonseca, Floriano Peixoto e dos cinco generais-ditadores desde 1964) e também pelo voto (como ocorreu com Hermes da Fonseca e Eurico Gaspar Dutra). No entanto, foi formado um governo com a presença de vários militares em diversas pastas ministeriais. Com as mudanças de cargos ocorridas ao longo do primeiro ano de governo e início do segundo, essa presença se ampliou em quantidade e qualidade, conforme se vê no quadro abaixo:

Quadro I - Ministros militares do governo Jair Bolsonaro em abril de 2020:

\begin{tabular}{|l|l|l|}
\hline Militar & Patente & Pasta ocupada \\
\hline Walter Souza Braga Netto & General da reserva & Ministério da Casa Civil \\
\hline Jorge de Oliveira Francisco & Polícia Militar do DF & Secretaria geral da Presidência \\
\hline Marcos Pontes & Tenente-coronel da FAB & Ministério da Ciência e Tecnologia \\
\hline Augusto Heleno Ribeiro Pereira & General da reserva & Gabinete de Segurança Institucional \\
\hline Fernando Azevedo e Silva & General da reserva & Ministério da Defesa \\
\hline Luiz Eduardo Ramos & General da ativa & Secretaria de governo \\
\hline Bento Costa Lima & Almirante & Ministério de Minas e Energia \\
\hline
\end{tabular}




\begin{tabular}{|l|l|l|}
\hline Wagner do Rosário & Capitão da reserva & Controladoria Geral da União \\
\hline
\end{tabular}

Fonte: BBC, 2020.

14 Nota-se no quadro acima como há uma vasta presença de militares na composição ministerial do governo Bolsonaro, contando atualmente oito das 22 pastas, ou 36,36\% de todas elas. Em números absolutos, a quantidade de ministérios ocupados por militares chega a superar os números dos governos da ditadura civil-militar liderados por Médici, Geisel e Figueiredo, igualando com a administração Costa e Silva e sendo inferiores à presença de integrantes das forças armadas no período Castello Branco. Há de se ponderar que durante a ditadura a quantidade de ministérios era menor, mas não chega a ser curioso que mais integrantes das forças armadas compunham o primeiro escalão do governo hoje do que no período da ditadura conduzida pelos militares. Devese destacar no quadro também a manutenção da pasta da Defesa sob liderança militar, além da presença desses agentes em postos-chave do coração político do governo. Assim, todos os ministros que despacham no palácio do Planalto - ministro-chefe da Casa Civil, secretário da Presidência, secretário de governo, chefe do GSI - são militares de formação. Isso parece prover um termômetro do grau da presença militar no governo. Importante salientar também que Braga Netto substituiu no dia 18 de fevereiro de 2020 o civil Onyx Lorenzoni no posto de ministro-chefe da Casa Civil. Assim, qualitativamente os militares ocupam cargos muito centrais na condução política do governo Bolsonaro.

15 Não só no primeiro escalão os militares passaram a ter uma presença cada vez maior no governo. Em áreas-chave eles têm ascendido em poder e presença, substituindo agentes civis e dotando algumas políticas públicas de feição militar, adequando-as à doutrina aprendida na caserna. Assim, recentemente foi reformulado o Conselho da Amazônia. Trata-se de uma organização governamental formada em 1995, subordinada ao Ministério do Meio Ambiente, e que servia para criar um lócus de debate para o desenvolvimento de políticas públicas para a região amazônica. Em abril de 2020, o conselho foi reordenado, sendo transferido do MMA para a vice-presidência da República, sob os auspícios do general da reserva Hamilton Mourão. Todos os governadores da região Norte foram retirados do conselho, bem como os representantes do Ibama (Instituto Brasileiro do Meio Ambiente e dos Recursos Naturais Renováveis) e da Funai (Fundação Nacional do Índio). A nova composição do conselho passou a ser exclusivamente militar, com 15 coronéis, sendo 12 do Exército e três da Aeronáutica, mais um general, dois majores-brigadeiros e um brigadeiro, além do próprio vice-presidente Mourão, também de formação militar (UOL, 2020). A militarização integral de um Conselho como esse parece revelar a escalada dos integrantes das forças armadas sobre a coisa pública, imprimindo a lógica militar ao Estado e políticas estatais. Além disso, essa militarização atende a certos projetos desenvolvidos no âmbito das forças armadas e que contemplam também objetivos e interesses econômicos específicos (INTERCEPT, 2019).

16 Houve, também, por parte de certos agentes militares, uma aproximação com os valores e concepções de mundo que embasam o "bolsonarismo". Assim, Eduardo Costa Pinto (2020) tem estudado o pensamento militar recente e encontrou alguns pensadores castrenses que têm elaborado ideias e reflexões similares às cultivadas pelo ideólogo do governo Bolsonaro, o "filósofo" Olavo de Carvalho. 


\section{Desenvolvendo a hipótese - possibilidade de aceleração da escalada militar no Estado brasileiro em meio ao surto do Covid-19}

17 Na atual crise da difusão do novo coronavírus no Brasil, parece haver uma chance real de uma resposta que aponte para um horizonte de intensificação do poder das forças armadas na condução do Estado e das políticas públicas no país. Em meio a uma desorganização flagrante do Estado brasileiro - que perdeu capacidade de condução política nos últimos anos, consoante a crise política do país e diante dos ataques das políticas neoliberais -, um dos segmentos do aparelho de Estado que parece dispor de uma capacidade organizativa ainda sustentada reside justamente nas forças armadas. Assim, a corporação militar parece entender que, dada a grave crise gerada pela difusão da doença gerada pelo vírus da Covid-19 no país, ela deve ser acionada para a administração da questão. Está claro que o sucesso dessa operação e a velocidade com que isso se dará estará umbilicalmente relacionado à própria dinâmica política do governo Bolsonaro, que não graça pela estabilidade desde que tomou posse e no momento político atual, em que os efeitos da difusão da epidemia devem ter efeitos sociais e humanitários bastante significativos. Martins Filho (2019) chama a atenção para o risco de Bolsonaro apelar para segmentos militares intermediários e inferiores, que compõem a base do bolsonarismo, podendo atuar como força a dividir a corporação militar, com segmentos mais radicalizados à direita politicamente na base da hierarquia, como já ocorreu em outros países e experiências históricas.

Os militares têm ascendido gradualmente em suas posições de mando e poder no Estado brasileiro nos últimos anos e têm alcançado um peso político que eles não dispunham desde o período da ditadura. $\mathrm{O}$ alastramento de uma epidemia no país pode proporcionar as circunstâncias ideais para a aceleração desse processo de escalada do poder militar sobre o Estado brasileiro. Um militar ocupando um cargo de mando não é simplesmente uma questão simbólica. Eles possuem uma formação distinta dos civis, no sentido de que são pautados na lógica do confronto e da existência de um inimigo que deve ser derrotado e destruído. Assim, é importante lembrar que historicamente as forças armadas no Brasil são educadas na noção da existência de um inimigo interno que deve ser exterminado. Segundo alguns autores (PINTO; GONÇALVES; SARDINHA; ESPERANÇA, 2020), isso foi aplicado pela primeira vez com o massacre de Canudos, de 1897, mas foi atualizado durante o período da Guerra Fria com a doutrina de segurança nacional e desenvolvimento, de acordo com a qual os comunistas eram os inimigos a serem exterminados (VASCONCELOS, 2020). Dessa forma, ao contrário do que certos discursos propagam, a tomada do governo pelos militares, em substituição à família Bolsonaro, não necessariamente vai apontar para um horizonte de diminuição da violência e atenuação da truculência por parte das ações estatais. Pelo contrário. Aplicando-se a lógica do inimigo interno - que não foi só praticada no passado remoto, mas também em situações recentes como nas ações de Garantia da Lei da Ordem (GLO) e nas intervenções militares em favelas e no Rio de Janeiro em 2019 -, muito provavelmente os setores sociais afetados negativamente pela escalada militar do governo são os integrantes das classes subalternas e os agentes de posições políticas diversas daquelas conservadoras cultuadas pelos militares. 
Por fim, é importante salientar a necessidade de novas pesquisas e mais estudos sobre os militares brasileiros, tendo em vista o protagonismo político que eles assumiram nos últimos anos. Após o fim da ditadura, vislumbramos que os militares voltariam aos quarteis e que suas incursões na vida pública do país tinham chegado a um fecho. Os fenômenos vividos nos últimos anos indicam que essa submersão foi passageira e que eles não devem ter voltado agora apenas de forma conjuntural a atuar na política, mas devem ter voltado para novamente gozar de um papel central na dinâmica da correlação de forças no país. Sendo assim, é urgente que pesquisadores se dediquem a investigar sua formação, seu desenvolvimento desde o fim da ditadura, pensamento, frações, organização e a inclinação à posição de novamente dispor de um protagonismo na cena política nacional brasileira.

\section{BIBLIOGRAFIA}

BOAS, Eduardo Villas. Publicação em sua rede social Twitter de 3 de abril de 2018. Disponível no endereço: https://twitter.com/Gen_VillasBoas

BRASIL DE FATO. Matéria: “O golpe de Estado na Bolívia tem a ver com a tela que você usa para ler este texto". Artigo de Vijay Prashad. Publicado em 21 de novembro de 2019. Disponível em: https://www.brasildefato.com.br/2019/11/21/o-golpe-na-bolivia-tem-a-ver-com-a-tela-quevoce-esta-usando-para-ler-este-artigo

COSTA, Simone Kawakami Gonçalves. A Geopolítica da Crise: uma análise da política estadunidense para a Primavera Árabe. Tese de doutoramento em Economia Política Internacional. Rio de Janeiro: UFRJ, 2020.

EL PAÍS. Matéria: "Merkel apela a cidadãos e chama coronavírus de 'maior desafio desde a Segunda Guerra Mundial"'. Por Ana Carbajosa, em 18 de março de 2020. Disponível em: https:// brasil.elpais.com/brasil/2020-03-18/merkel-pede-colaboracao-dos-cidadaos-diante-do-maiordesafio-desde-a-segunda-guerra-mundial.html

FERREIRA Neto, Walfredo Bento. Uma Estratégia Nacional de Defesa para Além da Guerra: geopolítica cibernética no Brasil e seu transbordamento econômico-tecnológico (2008-2016). Tese de doutorado em Economia Política Internacional. Rio de Janeiro: UFRJ, 2020 (no prelo).

G1. Matéria “Exército pede informações sobre capacidade de sepultamento de cidades no RJ". Por Bom Dia Rio, 17/04/2020. Disponível no endereço: https://g1.globo.com/rj/rio-de-janeiro/ noticia/2020/04/17/exercito-pede-informacoes-sobre-capacidade-de-sepultamento-de-cidadesdo-rj-dizem-prefeitos.ghtml

LEMOS, Renato Luis do Couto Neto e. Reformas institucionais na segurança pública e nas forças armadas. In: WESTHROP, Amy Jo; GARRIDO, Ayra Guedes; PARREIRA, Carolina Genovez; SANTOS, Shana Marques Prado dos (org.). As Recomendações da Comissão Nacional da Verdade: balanço sobre a sua implementação dois anos depois. Rio de Janeiro: Iser, 2016, p. 147-152.

LULA, Luís Inácio Lula da Silva. Entrevista ao jornalista Bob Fernandes. Divulgada em 16 de agosto de 2019. Disponível no endereço: https://www.youtube.com/watch?v=abux878rOAw 
MARTINS Filho, João Roberto. Entrevista com João Roberto Martins Filho: “Os militares estão em um governo de opereta. Eles se submeteram a constantes vexames, diz pesquisador". Entrevista concedida a Guilherme Pavarin e publicada em 24/06/2019. Disponível em: https:// theintercept.com/2019/06/23/entrevista-joao-roberto-martins-militares-bolsonaro/

PINTO, Eduardo Costa. Entrevista "Os militares e Bolsonaro". Publicada em 31 de março de 2020. Disponível no endereço: https://www.youtube.com/watch?v=VkOLM7LQIaE\&t=1011s

PINTO, Nalayne; GONÇALVES, Vinicius; ESPERANÇA, Vinicius; SARDINHA, Thiago. A militarização das cidades e a intervenção militar no Rio de Janeiro. In: CAMPOS, Pedro Henrique Pedreira; JORGE, Vladimyr Lombardo; ALVES Júnior, Antônio José (org.). o Golpe de 2016 e o Futuro da Democracia no Brasil: curso de extensão na UFRRJ. Seropédica: Edur, 2020 (no prelo).

STEPAN, Alfred. Os Militares na Política: as mudanças de padrões na vida brasileira. Rio de Janeiro: Artenova, 1975 [1971].

THE INTERCEPT. Matéria: “Movido a paranoia: documentos e áudios inéditos mostram o plano de Bolsonaro para povoar a Amazônia contra os chineses, ONGs e a Igreja Católica". Publicado em 20 de setembro de 2019. Disponível no endereço: https://theintercept.com/2019/09/19/planobolsonaro-paranoia-amazonia/

UOL. Matéria: “Mourão forma Conselho da Amazônia com 19 militares e sem Ibama e Funai'. Coluna de Rubens Valente, publicada em 18 de abril de 2020. Disponível em: https:// noticias.uol.com.br/colunas/rubens-valente/2020/04/18/conselho-amazonia-mourao.htm

VASCONCELOS, Cláudio Beserra de. "Os tecnoempresários, a ESG e a ditadura brasileira". In: CAMPOS, Pedro Henrique Pedreira; BRANDÃO, Rafael Vaz da Motta; LEMOS, Renato Luis do Couto Neto e (org.). Empresariado e Ditadura no Brasil. Rio de Janeiro: Consequência, 2020, no prelo.

\section{NOTAS}

1. No dia 3 de abril de 2018, o general publicou a seguinte mensagem em sua rede social: "Asseguro à Nação que o Exército Brasileiro julga compartilhar o anseio de todos os cidadãos de bem de repúdio à impunidade e de respeito à Constituição, à paz social e à Democracia, bem como se mantém atento às suas missões institucionais." (BOAS, 2018).

\section{RESUMOS}

O presente ensaio busca analisar o impacto do novo coronavírus no Brasil, desenvolvendo a hipótese de que a presente crise pode proporcionar as condições para a aceleração da escalada dos militares sobre o Estado brasileiro, um processo que vem ocorrendo desde a acentuação do impasse político no país, que se intensificou ao longo da última década. 0 texto aponta também para a probabilidade de essa emergência militar sobre o aparelho de Estado e as políticas públicas lesarem de forma mais significativa as classes subalternas e as forças políticas progressistas, além de indicar a necessidade de mais estudos sobre as forças armadas brasileiras no período atual, dado o desconhecimento acerca dos seus agentes e frações, bem como a escassez de especialistas que se dedicam ao assunto. 
This essay seeks to analyze the impact of the new coronavirus in Brazil, developing the hypothesis that the present crisis may provide the conditions for the acceleration of the military escalation over the Brazilian State, a process that has been occurring since the accentuation of the political impasse in the country, which has intensified over the past decade. The text also points to the probability that this military emergence over the State apparatus and public policies will more significantly harm the subordinate classes and progressive political forces, in addition to indicating the need for further studies on the Brazilian military in the current period, given the lack of knowledge about its agents and fractions, as well as the lack of specialists dedicated to the subject.

Este ensayo busca analizar el impacto del nuevo coronavirus en la sociedad brasileña, desarrollando la hipótesis de que la crisis actual puede proporcionar las condiciones para la aceleración de la escalada militar sobre el Estado brasileño, un proceso que ha estado ocurriendo desde la acentuación del estancamiento político em el pais, que se ha intensificado en la última década. El texto también señala la probabilidad de que este surgimiento militar sobre el aparato estatal y las políticas públicas perjudique más significativamente a las clases subordinadas y las fuerzas políticas progresistas, además de indicar la necesidad de más estudios sobre el ejército brasileño en el período actual. , dada la falta de conocimiento sobre sus agentes y fracciones, así como la falta de especialistas dedicados al tema.

Afin de comprendre l'impact du nouveau coronavirus au Brésil, on développe l'hypothèse selon laquelle la crise actuelle peut créer les conditions pour l'ampliation du rôle des militaires au sein de l'État Brésilien. Ce processus est en cours depuis les impasses politiques tout au long de la dernière décennie, et le résultat est l'affaiblissement des classes subalternes et des forces politiques progressistes. On souligne aussi le besoin d'amplifier les chercheurs et les études autour des militaires - y compris ses actions et ses groupes - dans le Brésil actuel.

\section{ÍNDICE}

Mots-clés: Covid-19; le nouveau coronavirus; Forces Armées; État Brésilien; militarisation Keywords: military; Covid-19; new coronavirus; armed forces; State; militarization Palabras claves: militar; Covid-19; nuevo coronavirus; fuerzas Armadas; Estado; militarizacion Palavras-chave: militares; Covid-19; novo coronavírus; forças armadas; Estado; militarização

\section{AUTOR}

\section{PEDRO HENRIQUE PEDREIRA CAMPOS}

Professor do Departamento de História da Universidade Federal Rural do Rio de Janeiro. Atua no Programa de Pós-Graduação de História da UFRRJ. E-mail: phpcampos@yahoo.com.br 